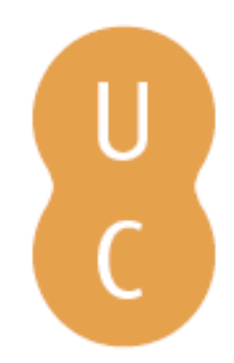

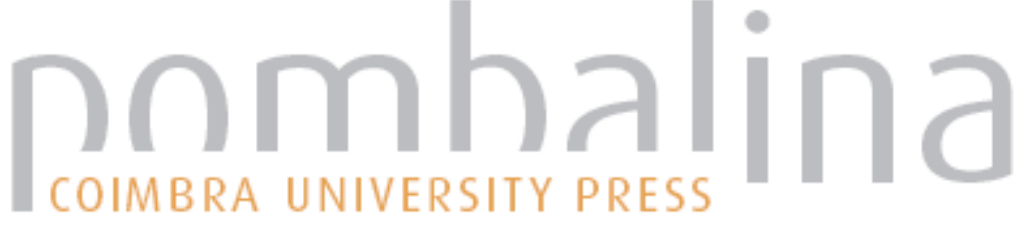

\section{Bibliotecária de universidade brasileira: testemunho de experiência}

Autor(es): $\quad$ Mattos, Suzete Moeda

Publicado por: Imprensa da Universidade de Coimbra

URL

persistente:

URI:http://hdl.handle.net/10316.2/36995

DOI:

DOI:http://dx.doi.org/10.14195/978-989-26-1045-0_24

Accessed : $\quad$ 26-Apr-2023 16:15:30

A navegação consulta e descarregamento dos títulos inseridos nas Bibliotecas Digitais UC Digitalis, UC Pombalina e UC Impactum, pressupõem a aceitação plena e sem reservas dos Termos e Condições de Uso destas Bibliotecas Digitais, disponíveis em https://digitalis.uc.pt/pt-pt/termos.

Conforme exposto nos referidos Termos e Condições de Uso, o descarregamento de títulos de acesso restrito requer uma licença válida de autorização devendo o utilizador aceder ao(s) documento(s) a partir de um endereço de IP da instituição detentora da supramencionada licença.

Ao utilizador é apenas permitido o descarregamento para uso pessoal, pelo que o emprego do(s) título(s) descarregado(s) para outro fim, designadamente comercial, carece de autorização do respetivo autor ou editor da obra.

Na medida em que todas as obras da UC Digitalis se encontram protegidas pelo Código do Direito de Autor e Direitos Conexos e demais legislação aplicável, toda a cópia, parcial ou total, deste documento, nos casos em que é legalmente admitida, deverá conter ou fazer-se acompanhar por este aviso. 

Tendo como pano de fundo as Comemorações dos seus 500 anos, a Biblioteca Geral da Universidade de Coimbra organizou um Congresso Internacional subordinado ao tema "A Biblioteca da Universidade: permanência e metamorfoses", que teve lugar nos dias 16, 17 e 18 de janeiro de 2014, no auditório da Reitoria da Universidade de Coimbra.

O objetivo maior desta reunião científica foi o de refletir sobre o presente e o futuro das bibliotecas que servem públicos universitários. Numa outra vertente, procurou chamar-se a atenção para a importância de que a Biblioteca se reveste, tendo em vista o progresso do conhecimento técnico e científico. Por último, o Congresso pretendeu instituir-se como oportunidade de reflexão prospetiva e como lugar de encontro entre as sensibilidades de todos os que trabalham profissionalmente com livros e com outros suportes de natureza bibliográfica.

Nesse sentido, foram apresentadas Conferências, Mesas Redondas e sessões de Testemunhos em torno de temas como o valor das bibliotecas universitárias, a biblioteca universitária em contexto; as mudanças e os desafios; a biblioteca universitária e a sociedade da informação e conhecimento; o impacto do acesso aberto na comunidade científica, e as bibliotecas digitais. 
SUZETE MOEDA MATTOS ${ }^{1}$

Universidade Federal do Estado do Rio de Janeiro

\section{BIBLIOTECÁRIA DE UNIVERSIDADE BRASILEIRA: TESTEMUNHO DE EXPERIEN CIA}

Em primeiro lugar, gostaria de agradecer o convite que me foi feito pelos organizadores do Congresso Internacional "A Biblioteca da Universidade: permanência e metamorfoses", em especial a José Augusto Cardoso Bernardes e Carla Ferreira. Devo adiantar que participar de um evento dessa magnitude é, sem dúvida, o grande sonho de qualquer bibliotecário brasileiro. Por sua vez, o tema do evento é sui generis, já que a Biblioteca Geral da Universidade de Coimbra vem se mantendo viva por um espaço temporal de quinhentos anos. O tema "permanência e metamorfoses" me remete de imediato para uma citação do famoso arcebispo brasileiro Dom Hélder Câmara, segundo o qual "um sonho sonhado por poucos é apenas um sonho, mas um sonho sonhado por muitos é o início da realidade."

O meu primeiro contato com o universo da Biblioteconomia se deu aos 14 anos de idade, em 1969, quando, numa aula inaugural do Curso de Biblioteconomia da Universidade Federal Fluminense - UFF, assisti a uma palestra proferida pela professora Leda Motta, cuja erudição e eloquência me atraiu a atenção para esse curso, me levando ao gosto pela leitura. Quatro anos mais tarde, em 1973, eu ingressava no Curso de Bacharelado em Biblioteconomia e Documentação dessa mesma universidade - UFF, onde trabalhei por 20 anos como bibliotecária, atuando no setor de Referência e Processamento Técnico. No exercício profissional, pude acompanhar as transformações tecnológicas da Universidade, desde o mimeógrafo a álcool até a digitalização de documentos, incluindo a Web.

\footnotetext{
1 A Autora escreve de acordo com a antiga ortografia.
} 
O Núcleo de Documentação, órgão gerenciador das bibliotecas universitárias da UFF, até a minha aposentadoria, em 1995, funcionava com 18 bibliotecas setoriais, e hoje conta com 27. O Núcleo era responsável pela formação e desenvolvimento de coleções, pelo processamento técnico e pela comutação bibliográfica, feita por meio de bônus da UNESCO, já que, na época, as universidades não tinham autonomia para importar material bibliográfico. Por oito anos atuei no processamento técnico do Núcleo, que até então era centralizado.

No meu trabalho de Referência, especificamente na biblioteca da Faculdade de Veterinária da UFF, realizei uma pesquisa com cinco alunos usuários de biblioteca, utilizando o método de observação direta. Foi nessa pesquisa que enfatizei a necessidade de autonomia por parte do usuário na busca da informação desejada. Apoiei-me no pensamento de Denis Grogan, para o qual um Serviço de Referência pode ser considerado como efetivo quando o bibliotecário se torna inútil.

Há aproximadamente doze anos o Ministério da Educação e Cultura do Brasil - MEC, vem realizando uma avaliação nas universidades brasileiras com uma metodologia bastante interessante, sob duas dimensões, uma individual e outra institucional. O primeiro é o Exame Nacional de Desempenho do Estudante - ENADE; o segundo avalia a estrutura organizacional das universidades, tais como laboratórios, bibliotecas, espaço físico, projeto pedagógico e corpo docente.

Durante o período em que exerci a profissão de bibliotecária, eu percebia que a biblioteca estava à parte do processo decisório da universidade. Isso fazia com que o bibliotecário fosse um profissional pouco valorizado na comunidade acadêmica, com reflexo negativo na sua remuneração salarial.

A partir de 1995, com o mestrado em Administração pela UFF já concluído, me aposentei como bibliotecária e ingressei na carreira docente. Em 2005, concluí o doutorado em Engenharia de Produção pela Universidade Federal do Rio de janeiro - UFRJ, sem deixar, contudo, de prestigiar as bibliotecas universitárias, com as quais mantenho vínculo ao longo do tempo, até porque, como professora da Universidade Federal do Estado 
do Rio de janeiro - UNIRIO, não poderia deixar de reconhecer o valioso trabalho desse organismo.

Após ter ouvido vários testemunhos no Congresso Internacional "A biblioteca da Universidade: permanência e metamorfoses" promovido pela Universidade de Coimbra em Portugal, é possível levantar uma questão que aflige a todos nós: qual seria a missão da biblioteca universitária? Arrisco dizer que ela é um espaço de aprendizagem cuja investigação parte de seus atores, bibliotecários/usuários. Ambos são colocados como sujeitos do processo que potencializa a biblioteca universitária como um lugar (sítio) de busca, criação e produção do conhecimento. Seria ainda possível questionar qual o papel do bibliotecário nesse contexto? Eu diria: romper com a forma de relação tradicionalista de doação de saberes, para o que é necessária a busca de um novo modelo de relação com a produção do conhecimento. Cabe ao bibliotecário um papel especial e único, com características próprias para o desenvolvimento de suas potencialidades como agente de mudanças e transformação.

Penso que a permanência da biblioteca universitária, entre outros fatores, está diretamente ligada à construção de uma outra significação (metamorfose) de biblioteca junto às universidades, e esta tarefa pertence a todos que participam do ofício impossível que é educar, inclusive do bibliotecário e à própria Escola de Biblioteconomia. Exemplo disso é a Biblioteca Geral da Universidade de Coimbra.

Concluo meu testemunho com uma oportuna citação do professor Roland Barthes:

"Há uma idade em que se ensina o que se sabe; mas vem em seguida outra em que se ensina o que não se sabe: isso se chama pesquisar. Vem talvez agora a idade de uma experiência, a de desaprender, de deixar trabalhar o remanejamento impossível que o esquecimento impõe à sedimentação dos saberes, das culturas, das crenças que atravessamos. Essa experiência tem, creio eu, um nome ilustre e fora de moda, que ousarei tomar aqui sem complexo na própria encruzilhada de sua etimologia: "Sapiência". Nenhum poder, um pouco de saber, um pouco de sabedoria, e o máximo de sabor possível”. 
José Augusto Cardoso Bernardes é Professor da Faculdade de Letras da Universidade de Coimbra e Diretor da Biblioteca Geral da Universidade

Ana Maria Eva Miguéis é coordenadora do Serviço Integrado das Bibliotecas da Universidade de Coimbra

Carla Ferreira é bibliotecária nos Serviços de Biblioteca e Documentação da Faculdade de Letras da Universidade de Coimbra. 


\section{Série Documentos}

Imprensa da Universidade de Coimbra

Coimbra University Press

2015

C •

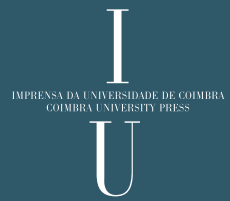

